\title{
黄瓜子叶有丝分裂与离体培美 反应关系的研究
}

钟华金 杜 勤 周利民 梁海曼

(杭州大学生物系,杭州 310012)

\section{关镜词黄瓜子叶、细盷分裂指数、离体培养、花芽分化}

我们在植物组织培养研究中发现适宜的培养基条件能使离体培养的黄瓜子叶分 化营养 芽、根及直接分化雌、雄花 ${ }^{[1-3]}$, 可作研究器官分化, 尤其花芽分化较理想的实验系统. 鉴于细 胞有丝分裂与细胞分化及而后的花器分化密切相关 ${ }^{[4-n}$, 以及细胞周期运转中内源细胞分裂素 水平有显著变化 ${ }^{[8]}$, 本文对黄瓜子叶不同部位细胞有丝分裂指数（MI）及细胞周期进行了较 系统研究,以期探索花芽分化的细胞学基础, 为进一步阐明花芽分化规律及其机理提供线索.

\section{1 材 料与方 法}

粒选饱满的黄瓜（Cucumis sativus L., CV Xia-Feng No. 2) 种子,经浸种后去种皮,接 种于 MS 无激素培养基上培养无落草。培养条件为 $25 \pm 1^{\circ} \mathrm{C}$, 光照强度 $15001 \mathrm{x}$ 。然后在正午 12 点分别切取培养 $1,3,5,7,9,11$ 天的种子苗子叶,接种于 MS (含 $1.5 \mathrm{mg} / \mathrm{L} \mathrm{KT}$ ) 培养基上 进行分化培养. 其中将 5 天苗龄的幼苗每隔 $1 \mathrm{~h}$ 切取子叶接秘作分化培养, 一天中共接种 24 次. 取分别培养 $24 \mathrm{~h}$ 的子叶作细胞学观察, 测定细胞分裂指数, 其操作程序如下：子叶于 $0.1 \%$ 秋水仙素中处理 $3 \mathrm{~h}$ (同培养温度) $\rightarrow$ 用水冲洗数次 $\rightarrow$ 在冰醋酸: 无水酒精 (3:1) 中固定 $5 \mathrm{~h} \rightarrow$ 用 $70 \%$ 酒精漂洗数次 $\rightarrow$ 转人解离液 (95\% 酒精: 浓盐酸 $=1: 1$ ) 中解离 $4 \mathrm{~min} \rightarrow$ 流水冲洗 $\rightarrow$ 用改良的苯酚品红染色 $\rightarrow$ 压片观察, 统计有丝分裂的细胞数. 每组观察 2000 个细胞, 并计算 有丝分裂指数,绘制有丝分裂在 $24 \mathrm{~h}$ 内的变化曲线。

\section{2 结果与讨论}

\section{1 黄瓜子叶不同部位的细盷有丝分裂指数}

将黄瓜子叶分为子叶柄 $(0.1-0.5 \mathrm{~cm})$ 、子叶基部 $(0.5 \mathrm{~cm})$ 和子叶 $(0.5 \mathrm{~cm}$ 以上)等三部分, 如表 1 所示: 子叶三个部分细胞有丝分裂指数相差悬殊, 其中子叶柄部细胞有丝分裂指数显 著地高于其它两部分. 分化培养结果已经证明离体培养黄瓜子叶的花牙分化集中发生于子叶 柄部分, 子叶上尚未见有任何花芽分化 ${ }^{[a, 2]}$. 一些报道指出: 细胞分裂增强时伴有内源细胞分 裂素和 IAA 水平升高的现象 ${ }^{[9-12]}$. 因此, 子叶柄部细胞有丝分裂指数极高与花芽(器官)分化 的关系是值得注意研究的.

\section{2 不同苗部幼苗子叶叶柄部位细胞分裂指数的差异}

表 1 表明黄瓜子叶叶柄部细胞有丝分裂指数在正午 12 点有一个分裂高峰.为此我们测定

1993-01-11 收稿, 1993-03-14 收修改稿. 
表 1 黄瓜子叶不同部位的细胞有丝分裂指数动态变化

\begin{tabular}{|c|c|c|c|c|c|c|}
\hline \multicolumn{2}{|c|}{$\begin{array}{l}\text { 分裂指数 (\%) }_{\text {材料 }} \text { (点) } \\
\end{array}$} & 8:00 & 9:00 & $10: 00$ & $11: 00$ & $12: 00$ \\
\hline $\begin{array}{c}7 \\
\text { at } \\
1\end{array}$ & $\begin{array}{l}\text { 子叶叶柄 }(0.1-0.5 \mathrm{~cm}) \\
\text { 子叶基部 }(0.5 \mathrm{~cm}) \\
\text { 子叶 }(0.5 \mathrm{~cm} \text { 以上 })\end{array}$ & $\begin{array}{c}0.03 \\
0 \\
0\end{array}$ & $\begin{array}{c}10.80 \\
1.05 \\
. \quad 0\end{array}$ & $\begin{array}{c}1.44 \\
0.01 \\
0\end{array}$ & $\begin{array}{l}2.10 \\
0.70 \\
0.01\end{array}$ & $\begin{array}{r}21.80 \\
2.10 \\
0.90\end{array}$ \\
\hline ? & $\begin{array}{l}\text { 子叶叶柄 }(0.1-0.5 \mathrm{~cm}) \\
\text { 子叶基部 }(0.5 \mathrm{~cm}) \\
\text { 子叶 }(0.5 \mathrm{~cm} \text { 以上 })\end{array}$ & $\begin{array}{c}0.10 \\
0.02 \\
0\end{array}$ & $\begin{array}{l}9.70 \\
1.10 \\
0.07\end{array}$ & $\begin{array}{c}1.50 \\
0 \\
0\end{array}$ & $\begin{array}{c}2.00 \\
0.10 \\
0\end{array}$ & $\begin{array}{r}19.00 \\
2.10 \\
0.20\end{array}$ \\
\hline $\begin{array}{l}\text { 子 } \\
\text { 计 } \\
\text { III }\end{array}$ & $\begin{array}{l}\text { 子叶叶柄 }(0.1-0.5 \mathrm{~cm}) \\
\text { 子叶基部 }(0.5 \mathrm{~cm}) \\
\text { 子叶 }(0.5 \mathrm{~cm} \text { 以上 })\end{array}$ & $\begin{array}{c}0.03 \\
0 \\
0\end{array}$ & $\begin{array}{r}10.00 \\
0.80 \\
0.10\end{array}$ & $\begin{array}{l}1.44 \\
0.10 \\
0.05\end{array}$ & $\begin{array}{c}2.10 \\
0.30 \\
0\end{array}$ & $\begin{array}{r}21.30 \\
1.10 \\
0.20\end{array}$ \\
\hline $\begin{array}{l}\text { 平 } \\
\text { 均 }\end{array}$ & $\begin{array}{l}\text { 子叶叶柄 }(0.1-0.5 \mathrm{~cm}) \\
\text { 子叶篦 }(0.5 \mathrm{~cm}) \\
\text { 子叶 }(0.5 \mathrm{~cm} \text { 以上 })\end{array}$ & $\begin{array}{c}0.053 \pm 0.023 \\
0.01 \pm 0.007 \\
0\end{array}$ & $\begin{array}{l}10.17 \pm 0.33 \\
0.98 \pm 0.09 \\
0.057 \pm 0.029\end{array}$ & $\begin{array}{l}1.48 \pm 0.018 \\
0.037 \pm 0.032 \\
0.017 \pm 0.016\end{array}$ & $\begin{array}{l}2.07 \pm 0.034 \\
0.37 \pm 0.18 \\
0.003 \pm 0.003\end{array}$ & $\begin{array}{l}20.7 \pm 0.58 \\
1.77 \pm 0.33 \\
0.43 \pm 0.23\end{array}$ \\
\hline
\end{tabular}

表 2 不同苗龄幼苗子叶叶柄部细胞有丝分裂指数的差异

\begin{tabular}{c|c|c|c|c}
\hline 苗略(天) & 第一次测定 & 第二次测定 & 第三次测定 & 平 均 \\
\hline 1 & 11.1 & 10.8 & 12.0 & $11.3 \pm 0.35$ \\
3 & 13.1 & 12.2 & 12.8 & $12.7 \pm 0.26$ \\
5 & 22.0 & 21.1 & 16.9 & $20.0 \pm 1.57$ \\
7 & 10.1 & 9.9 & 9.2 & $9.73 \pm 0.25$ \\
9 & 3.1 & 2.8 & 2.6 & $2.83 \pm 0.06$ \\
11 & 1.1 & 1.5 & 1.8 & $1.47 \pm 0.21$ \\
\hline
\end{tabular}

了 1,3, 5, 7, 9, 11 天苗龄的子叶叶柄部在正午 12 点的有丝分裂指数. 结果如表 2 和图 1 所 示: 不同苗龄子叶叶柄部的细胞分裂指数有 明显差异, 5 天苗龄的最高. 这一事实与在 分化培养中得到的结果即离体培养子叶的花 芽分化率以 4-5 天苗龄的子叶为最高 是 相 一致的 ${ }^{[1,2]}$.

\subsection{5 天苗跉的苏瓜子叶叶柄部细胞有丝分 裂指数的日 (24h) 变化}

鉴于子叶柄细胞分裂状况与其花芽的形 成可能存在相关, 我们进一步测定了具较高 花牙分化率的 5 天苗龄子叶叶柄部细胞分裂 指数的日 (24h) 变化. 结果如图 2 所示: 这 部分细胞的有丝分裂指数在一天 $24 \mathrm{~h}$ 内有显 著波动, 分裂最高峰在凌晨 2 点, 分裂指数为

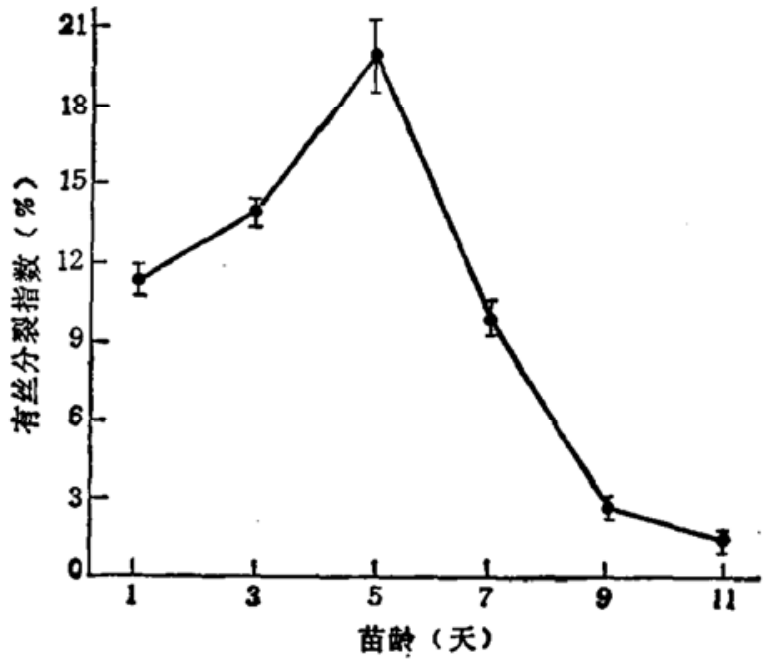

图 1 不同苗齢黄瓜子叶叶柄部细胞的有丝 分裂指数(根据表 2 数据绘制) $31.1 \%$ 左右; 次高峰在正午 12 点,分裂指数为 $20.0 \%$ 左右.以分裂高峰期具有相当高的分裂同 
步化程度表明离体培养的子叶表现出极其活跃的形态发生不是偶然的. 由于培养温度和 $24 \mathrm{~h}$ 光照均基本恒定, 可以认为分裂指数的日变化是反映了子叶本身的规律性变化, 与环境的影响: 关系不大. 图 2 还显示: 21 点至次日凌晨 2 点及凌晨 4 点至 8 点是全天中细胞分裂指数最 低的, 尤其是凌晨 2 点前后共 $12 \mathrm{~h}$, 除凌晨 2 点的分裂高峰外, 均为最低期. 鉴于细胞分化通常

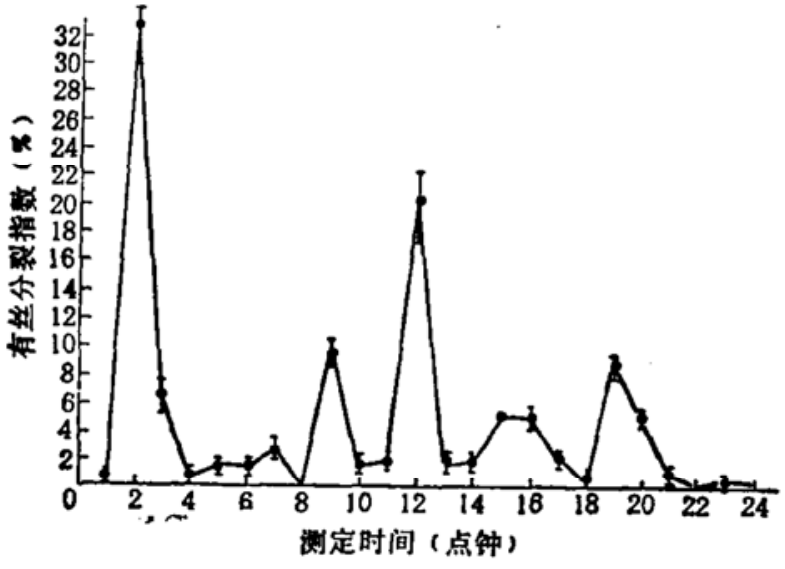

图 2 黄瓜子叶叶柄部细胞有丝分裂指数的日 (24h) 变化

是在细胞周期的特定时期开始的 ${ }^{[5,6]}$, 子叶在 一天中的不同时间离体进行分化培养可能会 产生不同的效果. 因此, 在一天 $24 \mathrm{~h}$ 中选择 何时为取样接种进行分化培养的最佳时间, 值得进一步研究. 从目前的结果看, 选择淩 晨 2 点左右或正午 12 点左右, 子叶细胞正处 于有丝分裂高峰的前后取样接种比较 合 适。 如考虑到便于实验操作,则选择正午 12 点左 右取样较为适宜.

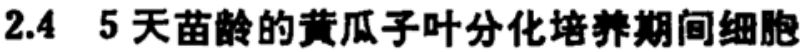 有丝分裂指数的变化}

每隔 $24 \mathrm{~h}$ 测定分化培养 5 天苗龄的黄瓜 子叶叶柄部位细胞在正午 12 点时的有丝分裂指数, 结果如表 3 和图 3 所示: 子叶叶柄部细胞 有丝分裂指数明显地随培养时间的增加而下降. 培养 12 天后下降到极低, 培养至 15 天几乎 接近于零. 联系分化培养试验结果: 子叶培养 20 天可见叶柄部直接形成花蕾 ${ }^{[1,2]}$, 培养 $12-$ 15 天正是启动黄瓜子叶器官(花芽)分化的时间. 因此, 子叶进人分化培养后的有丝分裂指数 变化时程值得注意. 这是否提示了细胞分裂活性的下降是细胞器官分化启动的前奏.

表 35 天苗龄的黄瓜子叶叶柄部细胞分化培养期间有丝分裂指数的变化

\begin{tabular}{l|ccccccccccccccccc}
\hline 培版天数 & 1 & 2 & 3 & 4 & 5 & 6 & 7 & 8 & 9 & 10 & 11 & 12 & 13 & 14 & 15 & 16 & 17 \\
\hline 有丝分裂细物数 & 95 & 90 & 82 & 82 & 71 & 72 & 59 & 43 & 30 & 28 & 11 & 6 & 4 & 4 & 0 & 1 & 0 \\
索丝分裂指数 & 19.0 & 18.0 & 16.4 & 16.4 & 14.2 & 14.4 & 11.8 & 8.6 & 6.0 & 5.6 & 2.2 & 1.2 & 0.8 & 0.8 & 0 & 0.2 & 0 \\
\hline
\end{tabular}

、) 每组材料齐察500个细胸.

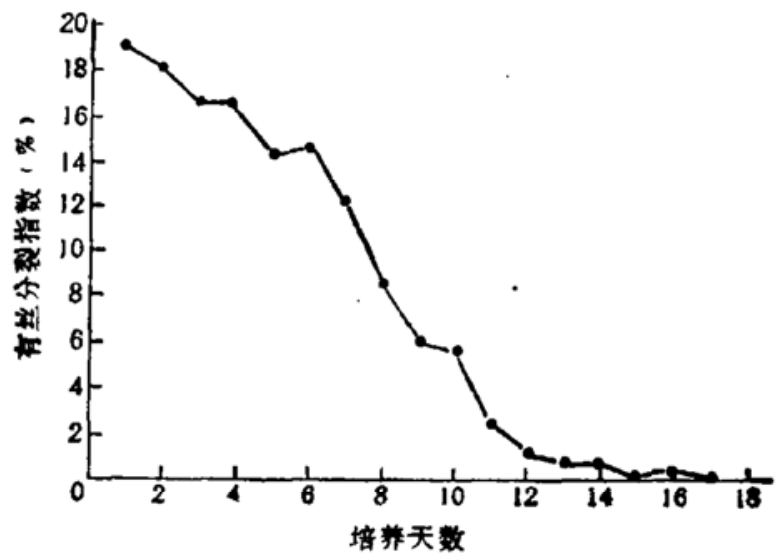

日3 黄瓜子叶在分化培养期间的细胞有丝分裂指数的变化(根据表 3 数据铨例) 
以上结果表明:（1)黄瓜子叶叶柄部细胞有丝分裂指数相当高,表现出不同于其它部位的 显著特点.（2)从苗龄和子叶的部位看, 细胞有丝分裂指数的峰值与离体培养子叶直接分化花 芽的频率峰值相符的, 这提示了黄瓜子叶的细胞分裂与分化有共同的生理基础. 因此从有丝 分裂和细胞周期状况着手研究黄瓜子叶直接开花的规律及机理,可提供十分有益的线索.

\section{参考文献}

[1] Pang Ji-liang Liang Hai-man, Liu Fei-yan et al, Chinese J. Bor. (在出版中).

[2] 周菊华、马月珍、罗紫姐等,科学通报, 1992, 37 (20): 1905-1908.

[3] 钟华全、赵映振、邹韧等,植物生理学通讯, 1993,29 (2): 98-100.

[ 4 ] Fukuda, H., Komamine, A., Physiol. Plant, 1981, 52(4): 423-430.

[ 5 ] Wille, J. J. Jr., Scott, B. E., J. Cell Physiol, 1982, 112(1): 115-122.

[6] Sharpe, P. T., Watts, D. S., Mol Cell Biochem., 1985, 67(1): 3-9.

[7] Szymkowiak, E. J., Sussex, I. M., The Plant Cell, 1992, 4(9): 1089-1100.

[ 8 ] Nishinari, N., Syono, K., Plant Cell Physiol., 1986, 27(1): 147-153.

[9] Nishinari, N., Yamaki, T., Bot. Mag, 1978, 91(1021): 93-95.

[10] Komamine, A., Morigaki, T., in Frontiers of Plant Tissue Gulture (ed. Thorpa, T. A.), 1978, $159-168$.

[11] Nishinari, N., Syono, K., Plant Cell Physiol, 1980,21(3): 383-393.

[12] Naleajima, H., Yokota, T., Takahashi, N. et al, Plant Cell Physiol, 1981, 22(8): $1405-1410$. 